\title{
Impact of exposure to cooking fuels on stillbirths, perinatal, very early and late neonatal mortality - a multicenter prospective cohort study in rural communities in India, Pakistan, Kenya, Zambia and Guatemala
}

\begin{abstract}
Archana B. Patel ${ }^{1 *}$, Sreelatha Meleth², Omrana Pasha ${ }^{3}$, Shivaprasad S. Goudar ${ }^{4}$, Fabian Esamai ${ }^{5}$, Ana L. Garces ${ }^{6}$, Elwyn Chomba', Elizabeth M. McClure ${ }^{2}$, Linda L. Wright ${ }^{8}$, Marion Koso-Thomas ${ }^{8}$, Janet L. Moore ${ }^{2}$, Sarah Saleem³ Edward A. Liechty ${ }^{9}$, Robert L. Goldenberg ${ }^{10}$, Richard J. Derman ${ }^{11}$, K. Michael Hambidge ${ }^{12}$, Waldemar A. Carlo ${ }^{13}$ and Patricia L. Hibberd ${ }^{14}$
\end{abstract}

\begin{abstract}
Background: Consequences of exposure to household air pollution (HAP) from biomass fuels used for cooking on neonatal deaths and stillbirths is poorly understood. In a large multi-country observational study, we examined whether exposure to HAP was associated with perinatal mortality (stillbirths from gestation week 20 and deaths through day 7 of life) as well as when the deaths occurred (macerated, non-macerated stillbirths, very early neonatal mortality (day 0-2) and later neonatal mortality (day 3-28).

Questions addressing household fuel use were asked at pregnancy, delivery, and neonatal follow-up visits in a prospective cohort study of pregnant women in rural communities in five low and lower middle income countries participating in the Global Network for Women and Children's Health's Maternal and Newborn Health Registry. The study was conducted between May 2011 and October 2012. Polluting fuels included kerosene, charcoal, coal, wood, straw, crop waste and dung. Clean fuels included electricity, liquefied petroleum gas (LPG), natural gas and biogas.
\end{abstract}

Results: We studied the outcomes of 65,912 singleton pregnancies, $18 \%$ from households using clean fuels (59\% LPG) and $82 \%$ from households using polluting fuels ( $86 \%$ wood). Compared to households cooking with clean fuels, there was an increased risk of perinatal mortality among households using polluting fuels (adjusted relative risk (aRR) 1.44, 95 \% confidence interval (CI) 1.30-1.61). Exposure to HAP increased the risk of having a macerated stillbirth (adjusted odds ratio (aOR) 1.66, 95\%Cl 1.23-2.25), non-macerated stillbirth (aOR 1.43, $95 \% \mathrm{Cl} 1.15-1.85$ ) and very early neonatal mortality (aOR $1.82,95 \% \mathrm{Cl} 1.47-2.22)$.

Conclusions: Perinatal mortality was associated with exposure to HAP from week 20 of pregnancy through at least day 2 of life. Since pregnancy losses before labor and delivery are difficult to track, the effect of exposure to polluting fuels on global perinatal mortality may have previously been underestimated.

Trial registration: ClinicalTrials.gov NCT01073475

Keywords: Perinatal, Neonatal, Mortality, Cooking fuels, Household air pollution

\footnotetext{
* Correspondence: dr_apatel@yahoo.com

'Lata Medical Research Foundation, Nagpur, Maharashtra 440022, India
}

Full list of author information is available at the end of the article 


\section{Background}

As progress continues to be made toward Millennium Development Goal \#4 (MDG4), attention increasingly focuses on causes of childhood mortality that have been the most resistant to improvement - particularly neonatal mortality (through day 28 of life) [1-4]. Reducing stillbirths (after week 20 of pregnancy and particularly intrapartum $[3,5]$ ) is not addressed in MDG\#4 (which focuses only on babies born alive) but the importance of reducing the burden of stillbirths, many of which may be resuscitatable at birth has been increasingly recognized [6].

Solid fuels and kerosene are used for cooking, heating and lighting by one third of the world's population [7]. Inefficient burning of these fuels results in household air pollution (HAP) that includes particulate matter and toxic chemicals, such as hydrocarbons, oxygenated organic compounds, free radicals and carbon monoxide [8]. HAP is the fourth leading risk factor for the global burden of disease, accounting for 3.5 million premature deaths in adults and children annually [7, 9]. HAP is a recognized risk factor for childhood pneumonia [10] and preterm birth [11], but the role of exposure to HAP on other pregnancy and neonatal outcomes is less clear due to concerns about the quality of evidence in the available observational studies [10]. This information is important as international governments are rolling out improved cookstoves that continue to use solid fuels without evidence on potential perinatal and other health benefits [12]. In addition, while there is a biologic basis for the effects of HAP on the developing fetus, neonate and young infant based on the similar pollutants in tobacco smoke (active and passive smoke exposure) [13-15], it is also unclear whether the effects of tobacco smoking and HAP are additive, synergistic or whether there is no interaction because the effect of one of the exposures (e.g., HAP) overwhelms the other (e.g., tobacco smoke).

The Eunice Kennedy Shriver National Institute of Child Health and Human Development's (NICHD's) Global Network (GN) for Women and Children's Health Research supports a Maternal and Newborn Health $(\mathrm{MNH})$ Registry of pregnant women and their babies living in rural communities in low and lower middle income countries. The Registry has focused on documentation of fetal loss after week 20 of pregnancy, accurate and timely measurement of birth, birth weight and early and late neonatal outcomes [16]. It provides an ideal population to address unanswered questions about risk factors for perinatal mortality as well as the timing of fetal loss or neonatal death. Thus our primary objective was to examine whether HAP from cooking with biomass fuels was associated with perinatal mortality (stillbirths from gestation week 20 and deaths through day 7 of life). Secondary objectives were to examine whether HAP exposure was a risk factor for macerated, non-macerated stillbirths, very early neonatal mortality (day 0-2 of life) and mortality from day 3-28 of life. We also address recent issues raised about the use of kerosene as a polluting fuel because of concerns that it has previously inappropriately considered a clean fuel [7].

\section{Methods}

\section{Ethics statement}

The MNH Registry is an ongoing prospective multicentre cohort study of pregnant women and their babies in 100 rural communities located in Guatemala, 2 states in India, Kenya, Pakistan and Zambia. Pregnant women are recruited as early as possible during pregnancy and followed through day 42 post-partum to obtain details about the pregnancy, labor and delivery and the health of the mother and infant. The study was reviewed and approved at all of the involved institutions' ethics review committees at: The Lata Medical Research Foundation, Nagpur, Maharashtra, India; Aga Khan University, Karachi, Pakistan; JN Medical College, Belgaum, Karnataka, India; Moi University School of Medicine, Eldoret, Kenya; IMSALUD, San Carlos University, Guatemala City, Guatemala; University Teaching Hospital, Lusaka, Zambia; Indiana University School of Medicine, Indianapolis, Indiana; Columbia University, New York, New York; Christiana Care, Newark, Delaware; University of Colorado, Aurora, Colorado; University of Alabama at Birmingham, Birmingham, Alabama; Partners IRB, Massachusetts General Hospital, Boston, Massachusetts and RTI International, Research Triangle Park, North Carolina. The study was registered at ClinicalTrials.gov (NCT01073475). A Data Monitoring Committee appointed by NICHD reviewed the registry data on at least an annual basis.

Pregnant women intending to deliver in the study communities or affiliated hospitals were informed about the study and invited to participate in the MNH Registry. Those who consented signed the IRB approved informed consent form.

\section{Study design, setting and participants}

We included pregnant women enrolled in the $\mathrm{MNH}$ Registry. We excluded women from households for which there was incomplete information on type of cooking fuel used in the household, multiple gestations, as well as women who had a medical termination of pregnancy or miscarriage before week 20 of pregnancy, and women who had incomplete information on maternal parity or age, or were lost to follow-up (Fig. 1).

Information is obtained at three time points in the registry. On enrolment (before the $20^{\text {th }}$ week of gestation), information on the date of last menstrual period, 


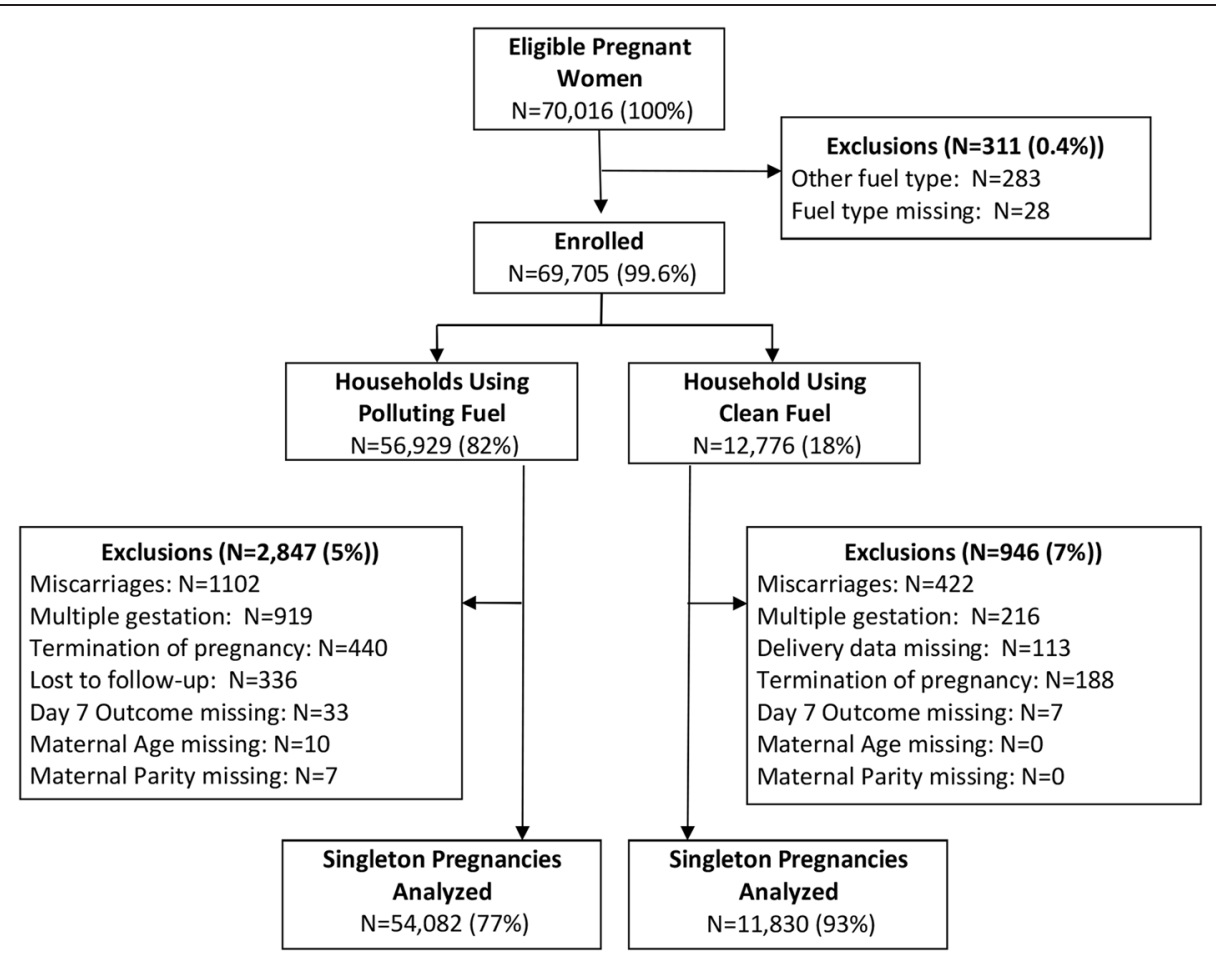

Fig. 1 Study flow diagram

estimated delivery date, age, education, parity, and status of last child is collected. Within 7 days of delivery, information is collected on prenatal care, birth preparedness, complications occurring during pregnancy, details of labor and delivery, including place, mode of delivery, provider, actual birth weight obtained at the time of birth, status of the mother and newborn following delivery, referrals, and treatment provided to the mother and newborn at referral facilities. Interval maternal and newborn health and status is assessed 42 days after birth. Birth weight is recorded for all babies (live born and still births) using locally available scales, calibrated per the local facilities. All study area birth attendants are trained to use and record accurate birth weights as described previously [16].

In May 2011, questions adapted from the Demographic Health Survey's (DHS) Household questionnaire, version 6 [17] on the type of fuel, location used for cooking and tobacco smoking in the household were added to the MNH Registry Questionnaire during the day 42 post-partum visit.

\section{Study variables Exposures}

Households using only electricity, liquefied petroleum gas, natural gas and biogas for cooking in their primary and secondary home (if they moved to a second location during pregnancy) were classified as homes using clean fuels. Households using all other fuels for cooking (kerosene, charcoal, coal, wood, straw, crop waste and dung) were classified as homes using polluting fuels. The location of cooking in the house was classified as in the house (separate kitchen or no separate kitchen), in a separate building or outside.

\section{Outcomes}

Primary Perinatal mortality - fetal loss after week 20 of pregnancy through day 7 of life (macerated stillbirths + non-macerated stillbirths + early neonatal mortality (NMR_0-7))/all pregnancies.

\section{Secondary}

(i) Macerated stillbirths/all pregnancies

(ii) Non-macerated stillbirths/all pregnancies

(iii) Very early neonatal mortality (NMR_0-2) through day 2 of life/all live births

(iv) Later neonatal mortality (NMR_3-28) from day 3-28 of life/all live births

A stillbirth was defined as birth of a baby after week 20 of gestation that had no signs of life at birth (no gasping, breathing, heart beat or movement). Stillbirths were further classified as macerated (death presumed before onset of labor, based on presence of discoloration and peeling of the skin leaving areas of raw tissue, an unusually soft skull, a dark red or black stained umbilical 
cord or darkly stained amniotic fluid) vs. non-macerated stillbirth (presumed intrapartum death and no signs of maceration).

\section{Covariates}

We collected data on the following covariates: maternal age $(<20, \geq 20)$; education (no formal education, any formal education); parity $(0,1-2, \geq 3)$; gestational age (preterm $(<37$ weeks) or term ( $\geq 37$ weeks) as assessed by last menstrual period, clinical examination, ultrasound, or other method); delivery location (hospital, clinic, home or other location); birth weight using available local scales; infant gender; and household tobacco use (anyone in the household smoking inside the house at least daily, less than daily smoking or no smokers in the household).

\section{Data source}

All study data were obtained by trained interviewers who recorded the response on case report forms. The interviewers were unaware of the study hypotheses.

\section{Statistical considerations}

Sample size The sample size calculations were based on the assumption that exposure to HAP would increase the risk of perinatal mortality by approximately 1.23 based on the lower $95 \%$ confidence interval of a previously reported odds ratios from a meta-analysis for stillbirths (there are no previously published data for perinatal mortality) and HAP of 1.5 (95\% CI 1.23, 1.85) [18]. Sample size was calculated conservatively and based on the lower level of the reported $95 \% \mathrm{CI}$, although kerosene was classified as a clean fuel in the meta-analysis, so this estimate is conservative. Based on the MNH Registry data for 2010 [16], we assumed a baseline perinatal mortality rate of $32 / 1000$ in the unexposed group. To detect an OR 1.23 (PMR of $37 / 1000$ or greater in the exposed group), significant at alpha $=0.05$ ( 2 sided), with $80 \%$ power, we estimated that we would need to collect outcome data on 61,530 singleton births.

Methods We first estimated population averaged effects of HAP on perinatal mortality using generalized estimating equations (GEE) to control for correlations within clusters. We fitted a modified Poisson regression model with a sandwich error estimation. All relative risks were adjusted for site due to the variability across the sites in the Global Network. Bivariate associations between covariates such as mother's age, mother's education, parity, ante-natal care, birth attendants at the delivery and mortality were evaluated by fitting a regression model that controlled for site and had mortality as the outcome and the covariate of interest as the predictor. We elected not to include low birth weight in the model as a covariate because it may be an intermediate step in the causal pathway between exposure to HAP and perinatal mortality [19-21]. All covariates with significant RRs were included in a final model that had PMR as the outcome and HAP as a predictor.

Since exposure to HAP would have differential effects on the fetus during pregnancy through the first month of life, particularly on macerated stillbirths, nonmacerated stillbirths, very neonatal mortality through day 2 of life (NMR_0-2) and later neonatal mortality from day 3-28 of life (NMR_3-28), we also modeled the data using multinomial logistic regression with a 5 level nominal outcome (macerated stillbirth, non-macerated stillbirth, NMR_0-2, NMR_3-28, alive after day 28). The model included exposure to HAP as the predictor and controlled for the same covariates as above. Low birth weight was excluded as explained above. We used the clustered bootstrap method [22] to estimate the variance of the estimates and create $95 \%$ confidence intervals.

\section{Results}

Between May 2011 and Oct 2012, we studied 65,912 pregnant women (Fig. 1). Mortality outcomes were available for 65,701 births (99.7 \%). There were 1,740 stillbirths (577 macerated and 1,163 non-macerated stillbirths) and 63,961 live births, of which 950 died on or before the second day of life, 275 died between the $3^{\text {rd }}$ and $7^{\text {th }}$ day of life, and 295 died between the $8^{\text {th }}$ and $28^{\text {th }}$ day of life). The distribution of the pregnancy outcomes by geographic location is shown in Fig. 2. Table 1 shows the demographic characteristics of the pregnant women, births and the households including details of the fuels used for cooking. A total of 54,082 (82 \%) pregnancies occurred in households using polluting fuel and $11,830(18 \%)$ in households using clean fuels. The distribution of pregnancies by types of fuel use and geographic location is shown in Fig. 3. LPG was the predominant type of clean fuel (59 \%) followed by natural gas (33\%) and wood was the predominant type of polluting fuel (86 \%).

The overall perinatal mortality rate was $48 / 1,000$ pregnancies $>20$ weeks gestation, ranging from 25/1,000 pregnancies in Guatemala to $90 / 1,000$ pregnancies in Pakistan. Table 2 shows the adjusted and unadjusted relative risks (RR) for exposure to HAP and covariates that were estimated using GEE in a Poisson regression model. The adjusted relative risk for perinatal mortality among babies whose mothers were exposed to HAP vs. clean fuels during pregnancy was 1.44 (95 \% CI 1.30, 1.61). Risk factors for perinatal mortality in the multivariate analysis, also adjusted for Global Network site, included cooking with polluting fuel, lack of maternal education (no formal schooling), nulliparity and 3 or 


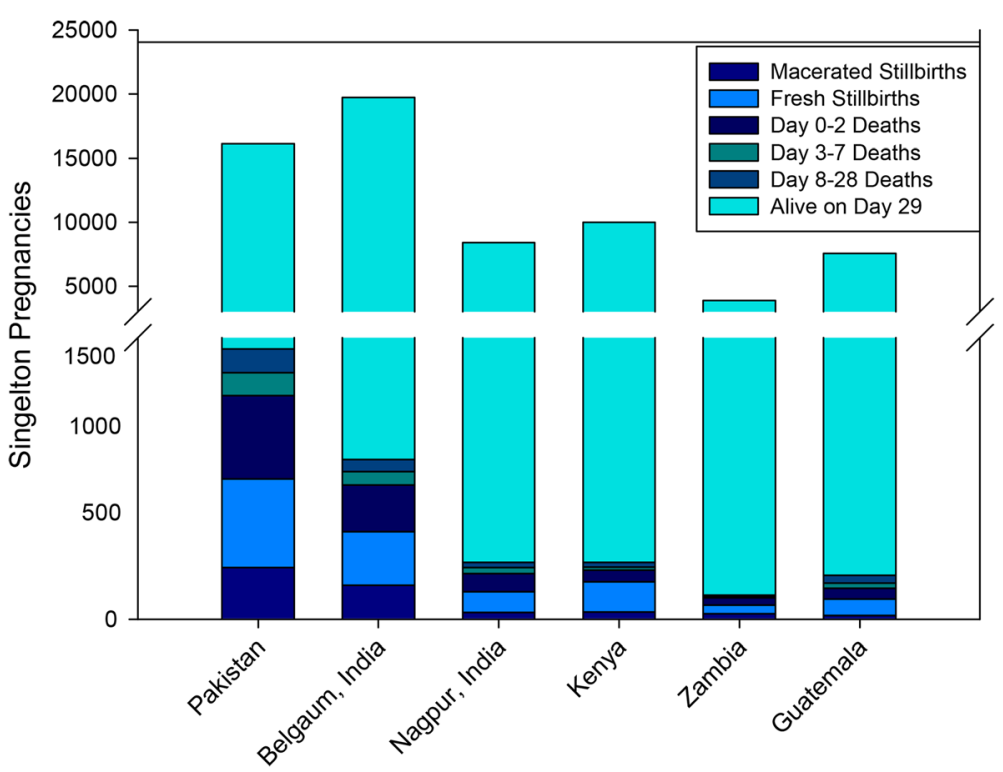

Fig. 2 Pregnancy outcomes by global network site

more prior births, no antenatal care, and male gender. Delivery by nurse or midwife or delivery unattended by a trained birth attendant was associated with lower perinatal mortality compared with delivery by a physician. Presence of anyone in the household who smoked on a daily basis was not associated with perinatal mortality.

Table 3 has the adjusted odds ratios (aOR) estimated using a multinomial logistic regression model. It shows the risk factors for the multi-level mortality variable (macerated and non-macerated stillbirths, very early neonatal deaths on days 0-2 (NMR_0-2) and later neonatal deaths days 3-28 (NMR_3-28) vs. alive on day 29). The aOR for having a macerated stillbirth in mothers exposed to HAP during pregnancy versus not exposed to HAP was 1.66 (95 \% CI 1.23, 2.25). The corresponding aOR for having a non-macerated stillbirth was 1.43 (95 \% CI 1.15, 1.85), very early neonatal mortality (NMR_0-2) was 1.82 (95 \% CI 1.47, 2.22) and later neonatal mortality (NMR_3-28) was 1.28 (95\% CI 0.91 , 1.76). Risk factors for having a macerated or nonmacerated stillbirth or very early neonatal mortality (NMR_0-2), also adjusted for Global Network site, included cooking with polluting fuel, nulliparity and 3 or more prior births. Delivery by nurse or midwife was associated with lower perinatal mortality compared with delivery by a physician. Lack of formal schooling was associated with having both a macerated and nonmacerated stillbirth and surprisingly, lack of antenatal care was only associated with having a non-macerated stillbirth. Male gender was associated with very early neonatal mortality (NMR_0-2) and later neonatal mortality (NMR_3-28), and nulliparity was also associated with later neonatal mortality. Presence of anyone in the household who smoked on a daily basis was not associated with having a still birth or neonatal death and was not included in the multivariate model.

\section{Discussion}

This study shows that in rural populations in five low resource countries, household use of polluting fuels for cooking increases the overall risk of perinatal mortality, after adjusting for maternal education, parity, antenatal visits, delivery location and attendant, and male gender. The important new finding of this research is that when the perinatal period of risk is divided into pre-partum (risk of having a macerated stillbirth), intrapartum (risk of having a non-macerated stillbirth) and postpartum (risk of neonatal death on day 0-2, 3-28 of life), exposure to HAP is associated with both types of stillbirths and early neonatal death through day 2 of life, not later neonatal death. These time periods were chosen for the secondary exploratory analyses (rather than early (day $0-7)$ and late (day 8-28) neonatal deaths) because there are few deaths after day 2 of life and we wanted to focus on the high mortality period between day 0 and 2 of life. Recognition of the risk of having a macerated fetus after week 20 of gestation is also important, as this outcome is not always recorded and may lead to an underestimate of the impact of exposure to HAP on adverse pregnancy outcomes.

Daily smoking in the household was not an independent predictor of perinatal mortality. It is possible that daily smoking was not an independent predictor of adverse pregnancy and neonatal outcome in our study 
Table 1 Demographic characteristics of the study subjects and households

\begin{tabular}{|c|c|c|c|c|c|c|c|}
\hline Characteristic & Pakistan & Belgaum, India & Nagpur, India & Kenya & Zambia & Guatemala & Total \\
\hline Maternal age & 16,235 & 19,728 & 8,443 & 9,973 & 3,876 & 7,554 & 65,809 \\
\hline$<20$ & $626(3.9)$ & $1,835(9.3)$ & $168(2.0)$ & $2,183(21.9)$ & $984(25.4)$ & $1,276(16.9)$ & $7,072(10.7)$ \\
\hline$\geq 20$ & $15,609(96.1)$ & $17,893(90.7)$ & $8,275(98.0)$ & $7,790(78.1)$ & $2,892(74.6)$ & $6,278(83.1)$ & $58,737(89.3)$ \\
\hline Maternal education & 16,239 & 19,611 & 8,439 & 9,974 & 3,847 & 7,555 & 65,665 \\
\hline No formal schooling & $13,595(83.7)$ & $4,464(22.8)$ & $216(2.6)$ & $295(3.0)$ & $422(11.0)$ & $1,610(21.3)$ & $20,602(31.4)$ \\
\hline Primary & $1,163(7.2)$ & $5,998(30.6)$ & $1,414(16.8)$ & $7,100(71.2)$ & $2,084(54.2)$ & $4,769(63.1)$ & $22,528(34.3)$ \\
\hline Secondary & $900(5.5)$ & $7,278(37.1)$ & $5,068(60.1)$ & $2,216(22.2)$ & $1,275(33.1)$ & $1,126(14.9)$ & $17,863(27.2)$ \\
\hline University+ & 581 (3.6) & $1,871(9.5)$ & 1,741 (20.6) & 363 (3.6) & $66(1.7)$ & $50(0.7)$ & $4,672(7.1)$ \\
\hline Parity & 16,238 & 19,384 & 8,446 & 9,976 & 3,876 & 7,554 & 65,474 \\
\hline 0 & $3,412(21.0)$ & $8,321(42.9)$ & $4,119(48.8)$ & $2,498(25.0)$ & $1,036(26.7)$ & $2,056(27.2)$ & $21,442(32.7)$ \\
\hline $1-2$ & $5,325(32.8)$ & $9,746(50.3)$ & $4,110(48.7)$ & $4,000(40.1)$ & $1,455(37.5)$ & $2,664(35.3)$ & $27,300(41.7)$ \\
\hline$\geq 3$ & $7,501(46.2)$ & $1,317(6.8)$ & $217(2.6)$ & $3,478(34.9)$ & $1,385(35.7)$ & $2,834(37.5)$ & $16,732(25.6)$ \\
\hline Antenatal care & 16,121 & 19,696 & 8,426 & 9,981 & 3,874 & 7,529 & 65,627 \\
\hline Any & $14,385(89.2)$ & $19,689(100.0)$ & $8,425(100.0)$ & $9,794(98.1)$ & $3,856(99.5)$ & $7,349(97.6)$ & $63,498(96.8)$ \\
\hline None & $1,736(10.8)$ & $7(0.0)$ & $1(0.0)$ & $187(1.9)$ & $18(0.5)$ & $180(2.4)$ & $2,129(3.2)$ \\
\hline Number of antenatal visits & 13,557 & 16,004 & 8,420 & 9,794 & 787 & 7,349 & 55,911 \\
\hline 1 & $2,889(21.3)$ & $954(6.0)$ & $108(1.3)$ & $468(4.8)$ & $124(15.8)$ & $365(5.0)$ & $4,908(8.8)$ \\
\hline 2 & $4,617(34.1)$ & $1,268(7.9)$ & $84(1.0)$ & $1,674(17.1)$ & $148(18.8)$ & $735(10.0)$ & $8,526(15.2)$ \\
\hline 3 & 3,359 (24.8) & $4,436(27.7)$ & $502(6.0)$ & $3,649(37.3)$ & $269(34.2)$ & 1,386 (18.9) & $13,601(24.3)$ \\
\hline$\geq 4$ & 2,692 (19.9) & $9,346(58.4)$ & $7,726(91.8)$ & $4,003(40.9)$ & $246(31.3)$ & $4,863(66.2)$ & $28,876(51.6)$ \\
\hline Delivery attendant & 16,266 & 19,755 & 8,444 & 9,991 & 3,881 & 7,555 & 65,892 \\
\hline Physician & $4,066(25.0)$ & $11,761(59.5)$ & $4,963(58.8)$ & $200(2.0)$ & $83(2.1)$ & $2,785(36.9)$ & $23,858(36.2)$ \\
\hline Nurse/Midwife & $4,312(26.5)$ & $7,055(35.7)$ & $3,249(38.5)$ & $3,944(39.5)$ & $2,067(53.3)$ & $197(2.6)$ & 20,824 (31.6) \\
\hline No skilled birth attendant & $7,888(48.5)$ & $939(4.8)$ & $232(2.7)$ & $5,847(58.5)$ & $1,731(44.6)$ & $4,573(60.5)$ & $21,210(32.2)$ \\
\hline Delivery location & 16,275 & 19,755 & 8,445 & 9,989 & 3,881 & 7,555 & 65,900 \\
\hline Facility & $8,624(53.0)$ & $18,673(94.5)$ & $8,186(96.9)$ & $4,012(40.2)$ & $2,340(60.3)$ & $2,960(39.2)$ & $44,795(68.0)$ \\
\hline Home/Other & $7,651(47.0)$ & $1,082(5.5)$ & $259(3.1)$ & $5,977(59.8)$ & $1,541(39.7)$ & $4,595(60.8)$ & $21,105(32.0)$ \\
\hline Infant gender & 16,135 & 19,722 & 8,390 & 9,983 & 3,873 & 7,551 & 65,654 \\
\hline Male & $8,472(52.5)$ & $10,335(52.4)$ & $4,353(51.9)$ & $5,069(50.8)$ & $2,038(52.6)$ & $3,816(50.5)$ & $34,083(51.9)$ \\
\hline Female & $7,663(47.5)$ & $9,387(47.6)$ & $4,037(48.1)$ & $4,914(49.2)$ & $1,835(47.4)$ & $3,735(49.5)$ & $31,571(48.1)$ \\
\hline Fuel used for cooking & 16,276 & 19,755 & 8,450 & 9,995 & 3,881 & 7,555 & 65,912 \\
\hline Electricity & $50(0.3)$ & $69(0.3)$ & $83(1.0)$ & $6(0.1)$ & $434(11.2)$ & $3(0.0)$ & $645(1.0)$ \\
\hline Liquified petroleum gas & $51(0.3)$ & $3,503(17.7)$ & $2,837(33.6)$ & $15(0.2)$ & $0(0.0)$ & $576(7.6)$ & $6,982(10.6)$ \\
\hline Natural gas & $3,861(23.7)$ & $3(0.0)$ & $16(0.2)$ & $29(0.3)$ & $2(0.1)$ & $27(0.4)$ & $3,938(6.0)$ \\
\hline Biogas & $11(0.1)$ & $95(0.5)$ & $123(1.5)$ & $23(0.2)$ & $0(0.0)$ & $5(0.1)$ & $257(0.4)$ \\
\hline Kerosene & $61(0.4)$ & $198(1.0)$ & $370(4.4)$ & $132(1.3)$ & $6(0.2)$ & $16(0.2)$ & $783(1.2)$ \\
\hline Coal & $13(0.1)$ & $3(0.0)$ & $61(0.7)$ & $4(0.0)$ & $0(0.0)$ & $3(0.0)$ & $84(0.1)$ \\
\hline Charcoal & $3(0.0)$ & $2(0.0)$ & $15(0.2)$ & $733(7.3)$ & $1,306(33.7)$ & $0(0.0)$ & $2,059(3.1)$ \\
\hline Wood & $11,968(73.5)$ & $11,735(59.4)$ & $4,589(54.3)$ & $9,033(90.4)$ & $2,120(54.6)$ & $6,925(91.7)$ & $46,370(70.4)$ \\
\hline Straw, etc. & $84(0.5)$ & $369(1.9)$ & $98(1.2)$ & $18(0.2)$ & $1(0.0)$ & $0(0.0)$ & $570(0.9)$ \\
\hline Agricultural crop & $19(0.1)$ & $2,398(12.1)$ & $179(2.1)$ & $2(0.0)$ & $0(0.0)$ & $0(0.0)$ & 2,598 (3.9) \\
\hline Animal dung & $154(0.9)$ & $1,380(7.0)$ & $78(0.9)$ & $0(0.0)$ & $0(0.0)$ & $0(0.0)$ & $1,612(2.4)$ \\
\hline No food cooked in household/other & $1(0.0)$ & $0(0.0)$ & $1(0.0)$ & $0(0.0)$ & $12(0.3)$ & $0(0.0)$ & $14(0.0)$ \\
\hline
\end{tabular}


Table 1 Demographic characteristics of the study subjects and households (Continued)

\begin{tabular}{llllllll}
\hline Smoking in primary household & 16,272 & 19,667 & 8,439 & 9,993 & 3,858 & 7,555 & 65,784 \\
Daily & $5,967(36.7)$ & $3,446(17.5)$ & $2,297(27.2)$ & $905(9.1)$ & $1,065(27.6)$ & $123(1.6)$ & $13,803(21.0)$ \\
Less than daily & $259(1.6)$ & $982(5.0)$ & $1,681(19.9)$ & $1,537(15.4)$ & $232(6.0)$ & $370(4.9)$ & $5,061(7.7)$ \\
No smoking & $10,046(61.7)$ & $15,239(77.5)$ & $4,461(52.9)$ & $7,551(75.6)$ & $2,561(66.4)$ & $7,062(93.5)$ & $46,920(71.3)$ \\
Cooking location for primary household & 16,272 & 19,666 & 8,430 & 9,992 & 3,858 & 7,555 & 65,773 \\
In the house & $4,010(24.6)$ & $19,280(98.0)$ & $7,768(92.1)$ & $2,693(27.0)$ & $860(22.3)$ & $956(12.7)$ & $35,567(54.1)$ \\
In a separate building & $9,149(56.2)$ & $284(1.4)$ & $559(6.6)$ & $6,930(69.4)$ & $2,462(63.8)$ & $3,424(45.3)$ & $22,808(34.7)$ \\
Outdoors & $3,110(19.1)$ & $100(0.5)$ & $102(1.2)$ & $367(3.7)$ & $519(13.5)$ & $3,172(42.0)$ & $7,370(11.2)$ \\
Other & $3(0.0)$ & $2(0.0)$ & $1(0.0)$ & $2(0.0)$ & $17(0.4)$ & $3(0.0)$ & $28(0.0)$ \\
\hline
\end{tabular}

because the exposure for most pregnant women in the rural communities studied was likely second hand smoke and exposure of the fetus and young infant to pollutants from second hand smoke would be much lower than the exposure to pollutants from household use of polluting fuel, although both second hand smoke and exposure to HAP has been associated with poor pregnancy outcomes in a prior Global Network study [23]. These different results may have been due to the specific DHS questions that were asked in this study, while the prior Global Network study asked questions adapted from the Global Youth Tobacco Survey, the 2000 US National Health Interview Survey and the Smoke-free Families Screening form. The DHS questions did not include maternal use of smokeless tobacco, which could be a risk factor for stillbirths or other adverse pregnancy outcomes. This is a limitation of our study. In future studies, it will be important to measure urine cotinine to assess actual exposure to tobacco smoke and smokeless tobacco.
Our data on the other independent risk factors for fetal or neonatal death are similar to those reported by others including no formal schooling, nulliparity and 3 or more prior births and no antenatal care visits $[24,25]$. Male gender is well recognized as a risk factor particularly for neonatal mortality, [26] associated with the biological survival advantage of girls in the neonatal period. Physician assisted deliveries of women from rural communities is often due to referral of women with high risk conditions to a higher level of care. So the reduced risk of perinatal mortality associated with nonphysician delivery attendants may be due to more complicated deliveries being done by physicians.

A major limitation of studies included in Pope et al's meta-analysis [18] is the lack of a clear definition of stillbirth. A strength of this study is the accurate and complete recording of stillbirths (macerated and nonmacerated) and timing of neonatal mortality by trained health care workers. However, our study has several limitations. Firstly, almost all published studies examining

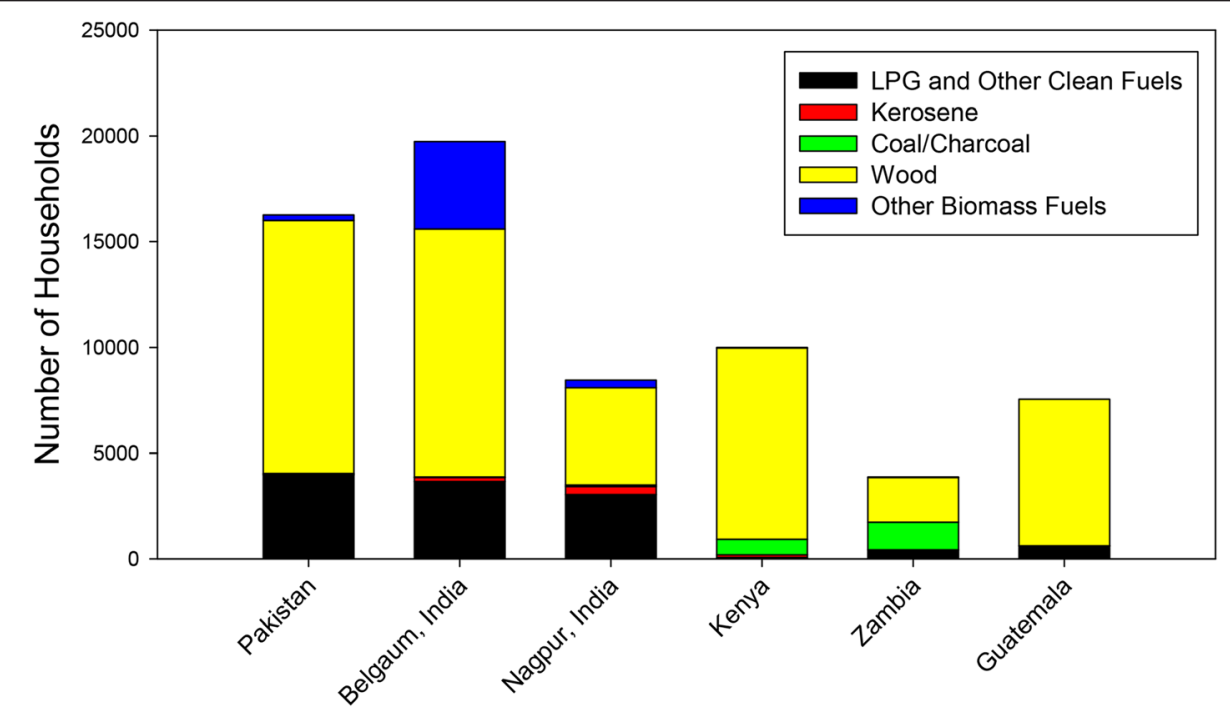

Fig. 3 Fuel use by global network site 
Table 2 Risk factors for perinatal mortality

\begin{tabular}{|c|c|c|c|c|}
\hline \multirow[t]{2}{*}{ Characteristic } & \multirow{2}{*}{$\begin{array}{l}\text { Perinatal mortality } \\
\text { (through day } 7 \text { of life) } \\
\mathrm{N}=3,176 \mathrm{n}(\%)\end{array}$} & \multirow{2}{*}{$\begin{array}{l}\text { Alive on day } 8 \text { of life } \\
N=62,736 n(\%)\end{array}$} & \multirow{2}{*}{$\begin{array}{l}\text { Relative risk adjusted for global } \\
\text { network site and community } \\
\text { (95\% confidence interval) }\end{array}$} & \multirow[t]{2}{*}{$\begin{array}{l}\text { Multivariate analysis - adjusted relative } \\
\text { risk ( } 95 \% \text { confidence interval) }\end{array}$} \\
\hline & & & & \\
\hline HAP exposure & 3,176 & 62,736 & & \\
\hline Polluting fuel & 2,683 (84) & $51,399(82)$ & $1.36(1.25,1.49)$ & $1.44(1.30,1.61)$ \\
\hline Clean fuel & $493(16)$ & $11,337(18)$ & 1.00 & 1.00 \\
\hline Maternal age & 3,172 & 62,637 & & \\
\hline$<20$ & $294(9)$ & $6,778(11)$ & $1.14(1.01,1.29)$ & $1.03(0.90,1.18)$ \\
\hline$\geq 20$ & 2,878 (91) & $55,859(89)$ & 1.00 & 1.00 \\
\hline Maternal education & 3,168 & 62,497 & & \\
\hline No formal schooling & $1,589(50)$ & $19,013(30)$ & $1.27(1.12,1.45)$ & $1.32(1.15,1.52)$ \\
\hline Formal schooling & $1,579(50)$ & $43,484(70)$ & 1.00 & 1.00 \\
\hline Parity & 3,154 & 62,320 & & \\
\hline 0 & 1,079 (34) & $20,363(33)$ & $1.36(1.25,1.47)$ & $1.33(1.21,1.45)$ \\
\hline $1-2$ & $1,053(33)$ & $26,247(42)$ & 1.00 & 1.00 \\
\hline$\geq 3$ & $1,022(32)$ & $15,710(25)$ & $1.27(1.16,1.39)$ & $1.26(1.13,1.40)$ \\
\hline Antenatal care & 3,147 & 62,480 & & \\
\hline Any & 2,906 (92) & $60,592(97)$ & 1.00 & 1.00 \\
\hline None & $241(8)$ & $1,888(3)$ & $1.49(1.28,1.73)$ & $1.35(1.15,1.58)$ \\
\hline Delivery attendant & 3,166 & 62,726 & & \\
\hline Physician & $1,236(39.0)$ & $22,622(36.1)$ & 1.00 & 1.00 \\
\hline Nurse/Midwife & $861(27.2)$ & $19,963(31.8)$ & $0.72(0.62,0.83)$ & $0.66(0.57,0.77)$ \\
\hline No skilled birth attendant & $1,069(33.8)$ & $20,141(32.1)$ & $0.79(0.67,0.95)$ & $0.58(0.41,0.80)$ \\
\hline Delivery location & 3,176 & 62,724 & & \\
\hline Facility & $2,108(66)$ & $42,687(68)$ & 1.00 & 1.00 \\
\hline Home/Other & $1,068(34)$ & $20,037(32)$ & $0.96(0.83,1.12)$ & $1.05(0.77,1.44)$ \\
\hline Infant gender & 2,934 & 62,720 & & \\
\hline Male & $1,677(57)$ & $32,406(52)$ & $1.22(1.13,1.32)$ & $1.21(1.11,1.31)$ \\
\hline Female & $1,257(43)$ & $30,314(48)$ & 1.00 & 1.00 \\
\hline Daily smoking in household & 3,175 & 62,721 & & \\
\hline Yes & $888(28)$ & $14,547(23)$ & $1.02(0.92,1.13)$ & \\
\hline No & $2,287(72)$ & $48,174(77)$ & 1.00 & \\
\hline
\end{tabular}

the effect of HAP on perinatal mortality [24, 27-31], including ours, have used the type of fuel used for cooking as a proxy for exposure to HAP. We focused on fuels used for cooking, as fuels are rarely used for heating in our Global Network sites, and did not adjust for whether cooking occurred inside or outside the household because where the cooking occurred was confounded by Global Network site. There is also some variation with the way household air pollution is categorized in prior studies, although most compare the relatively homogeneous group of clean fuels with the heterogeneous group of polluting fuels, as we did. Risk of perinatal mortality likely varies by fuel type, in part because pollutants vary by fuel type e.g., kerosene smoke pollutants are quite different from wood smoke pollutants [24]. Unfortunately, we could not analyze data on kerosene separately because only $1 \%$ of our households used kerosene. We would have also preferred to analyse data on wood smoke and coal/charcoal as additional separate categories, but use of wood as a cooking fuel was confounded with global network location and only $3 \%$ of households used coal/charcoal as a cooking fuel. In future studies, it will be important to measure particulate matter and other pollutants associated with biomass fuels. Secondly, we were only able to control for variables collected for the $\mathrm{MNH}$ Registry and specifically, we were not able to adequately control for socioeconomic status, which can be associated with pregnancy outcomes. Biomass fuels, 
Table 3 Risk factors for the multilevel mortality variable

\begin{tabular}{|c|c|c|c|c|c|}
\hline \multirow[t]{2}{*}{ Characteristic } & \multicolumn{5}{|c|}{ Multivariate analysis - adjusted odds ratios (95 \% Confidence Interval) } \\
\hline & $\begin{array}{l}\text { Macerated } \\
\text { stillbirths }\end{array}$ & $\begin{array}{l}\text { Non-Macerated } \\
\text { stillbirths }\end{array}$ & $\begin{array}{l}\text { Early neonatal mortality } \\
\text { day 0-2 of life (NMR_0-2) }\end{array}$ & $\begin{array}{l}\text { Later neonatal mortality } \\
\text { day 3-28 of life (NMR_3-28) }\end{array}$ & $\begin{array}{l}\text { Alive on day } 29 \\
\text { (Reference Group) }\end{array}$ \\
\hline \multicolumn{6}{|l|}{ HAP exposure } \\
\hline Polluting fuel & $1.66(1.23,2.25)$ & $1.43(1.15,1.85)$ & $1.82(1.47,2.22)$ & $1.28(0.91,1.76)$ & 1.00 \\
\hline Clean fuel & 1.00 & 1.00 & 1.00 & 1.00 & 1.00 \\
\hline \multicolumn{6}{|l|}{ Maternal age } \\
\hline$<20$ & $0.83(0.55,1.13)$ & $1.01(0.81,1.24)$ & $1.21(0.97,1.48)$ & $1.05(0.78,1.42)$ & 1.00 \\
\hline$\geq 20$ & 1.00 & 1.00 & 1.00 & 1.00 & 1.00 \\
\hline \multicolumn{6}{|l|}{ Maternal education } \\
\hline No formal schooling & $1.71(1.32,2.22)$ & $1.51(1.26,1.81)$ & $1.14(0.90,1.44)$ & $1.19(0.95,1.47)$ & 1.00 \\
\hline Formal schooling & 1.00 & 1.00 & 1.00 & 1.00 & 1.00 \\
\hline \multicolumn{6}{|l|}{ Parity } \\
\hline 0 & $1.27(1.03,1.59)$ & $1.34(1.13,1.56)$ & $1.24(1.05,1.47)$ & $1.43(1.17,1.73)$ & 1.00 \\
\hline $1-2$ & 1.00 & 1.00 & 1.00 & 1.00 & 1.00 \\
\hline$\geq 3$ & $1.30(1.01,1.68)$ & $1.39(1.19,1.65)$ & $1.22(1.04,1.43)$ & $1.11(0.86,1.41)$ & 1.00 \\
\hline \multicolumn{6}{|l|}{ Antenatal care } \\
\hline Any & 1.00 & 1.00 & 1.00 & 1.00 & 1.00 \\
\hline None & $1.41(0.99,2.12)$ & $1.62(1.23,2.13)$ & $0.90(0.68,1.21)$ & $1.32(0.85,1.81)$ & 1.00 \\
\hline \multicolumn{6}{|l|}{ Delivery attendant } \\
\hline Physician & 1.00 & 1.00 & 1.00 & 1.00 & 1.00 \\
\hline Nurse/Midwife & $0.69(0.52,0.87)$ & $0.65(0.51,0.82)$ & $0.68(0.54,0.85)$ & $0.87(0.70,1.08)$ & 1.00 \\
\hline No skilled birth attendant & $0.58(0.25,1.03)$ & $0.50(0.30,0.80)$ & $0.67(0.39,1.00)$ & $0.91(0.49,1.67)$ & 1.00 \\
\hline \multicolumn{6}{|l|}{ Delivery location } \\
\hline Facility & 1.00 & 1.00 & 1.00 & 1.00 & 1.00 \\
\hline Home/Other & $0.94(0.49,2.30)$ & $1.06(0.70,1.68)$ & $1.00(0.72,1.71)$ & $0.86(0.48,1.48)$ & 1.00 \\
\hline \multicolumn{6}{|l|}{ Infant gender } \\
\hline Male & $1.08(0.91,1.30)$ & $1.13(0.99,1.29)$ & $1.39(1.19,1.60)$ & $1.18(1.00,1.40)$ & 1.00 \\
\hline Female & 1.00 & 1.00 & 1.00 & 1.00 & 1.00 \\
\hline
\end{tabular}

especially fire wood collected from the forests, are used in impoverished rural homes because it is readily available and cheap [32]. The measure of socioeconomic status for this study was level of education and antenatal visits, while we did control for these proxy variables, residual confounding is possible. Although the Global Network has attempted to obtain details of maternal health before and during pregnancy (e.g., pre-pregnancy body mass index), there are limitations to the validity of these data and we are unable to address the impact of maternal conditions and BMI on pregnancy outcomes. Similarly, we do not have valid information on the neonate's nutritional status and cannot address the effect of this confounder on perinatal mortality. Finally, we recognize that since information on exposure to cooking fuels and smoking and confounding variables were collected on day 42 postpartum, there is a potential for recall bias, which is an additional limitation.
The association between polluting fuel and perinatal mortality mediated by LBW is biologically plausible based on studies of the effects of tobacco smoking, outdoor air pollution and animal studies, but the precise mechanisms by which the varying types of HAP cause perinatal mortality and LBW is not clear. We examined the possibility of LBW being a mediator on the causal pathway between HAP and mortality using mediation analysis as follows. We assumed a causal pathway between HAP and PMR and tested to determine whether LBW contributes to the increased PMR in HAP households. In order to do this, we regressed HAP on LBW controlling for site $(\mathrm{RR}=1.17(1.10,1.24), p<0.0001)$; we then regressed HAP on PMR while controlling for LBW. The RR for HAP in the model that controls for LBW was attenuated by about $9 \%$ (1.34 to 1.22). If LBW were the only variable on the causal pathway, then introducing LBW into the model with HAP and PMR 
would explain all of the variability in PMR, LBW would be a significant predictor and HAP would become nonsignificant in the model. Since the RR is attenuated but still significant, it suggests that some of the increased PMR in HAP households is due to LBW associated with HAP. The mediation effect of LBW on the causal pathway was further tested with Sobel's test. The value of Sobel's z- statistic was $5.08, p<0.0001$ confirming that LBW was a mediator in the causal pathway between HAP and PMR. Although the statistical analysis suggests that LBW is probably a mediator on the causal pathway, we do not have any data collected in this study to confirm or deny this. Similarly, preterm, birth defects, and maternal and neonatal complications might be on the causal pathway between exposure to HAP and mortality, or could be confounders. The statistical modelling technique to determine whether a variable is a confounder or a mediator is the same. Since we did not have any data to confirm whether it was one or the other, we decided that it would be better to exclude these variables from the model. Future research should focus on collecting data that will help to clarify these relationships.

Polyaromatic hydrocarbons (PAH) can cross the placenta and reach fetal organs [33-43]. These compounds may interfere with placental development and nutrient and oxygen delivery to the fetus [44, 45]. DNA-adduct levels of PAH in cord blood leukocytes have been linked with decreased birth weight, length, and head circumferences [46, 47]. PAH, metals, and related compounds can induce the production of cytotoxic reactive oxygen species and, ultimately, inflammatory and oxidant stress responses $[48,49]$. Ultrafine particles are potent inducers of cellular heme oxygenase- 1 expression and deplete intracellular glutathione, both also important in oxidant stress responses [50]. Stress responses and proinflammatory cytokines may also trigger preterm birth [51, 52], although at the maternal fetal interface, not systemically [53]. Carbon monoxide from combustion of any biomass and fossil fuels have been linked with intrauterine growth restriction, possibly as a result of carboxyhemoglobin limiting oxygen delivery to fetal tissue [54]. Early and late neonatal mortality may be caused by neonatal pneumonia.

\section{Conclusions}

In September 2010, the United Nations Foundation announced the Global Alliance for Clean Cook Stoves, a new public-private partnership to save lives, empower women, improve livelihoods, and combat climate change by creating a thriving global market for clean and efficient household cooking solutions. The Alliance's ' 100 by 20 ' goal calls for 100 million homes to adopt clean, efficient stoves and fuels by 2020 . Already there is great urgency to implement improved stoves and fuels and so there is imminent need to evaluate whether these new stoves actually do save lives [12]. Our study documents that in rural locations in five low and low-middle income countries where use of polluting fuel is widespread, large numbers of pregnant women will need to be studied to determine whether improved cook-stoves and fuels that reduce exposure to HAP also reduces perinatal mortality, LBW and neonatal mortality.

\section{Abbreviations}

aOR: Adjusted odds ratio; aRR: Adjusted relative risk; Cl: Confidence interval; DHS: Demographic Health Survey; GN: Global Network; HAP: Household air pollution; LBW: Low birth weight; MDG4: Millennium Development Goal \#4; MNH: Maternal Newborn Health; NICHD: Eunice Kennedy Shriver National Institute of Child Health and Human Development; NMR_0-2: Very early neonatal mortality day 0-2; NMR_0-7: Early neonatal mortality day 0-7; NMR_3-28: Later neonatal mortality day 3-28; OR: Odds ratio; PAH: Polyaromatic hydrocarbons; PMR: Perinatal mortality rate - deaths from week 20 of gestation through day 7 of life; RR: Relative risk.

\section{Competing interests}

The authors declare that they have no competing interests.

\section{Authors' contributions}

ABP, SM, LLW, MKT, EMM and PLH developed the protocol with input from $\mathrm{OP}, \mathrm{SSG}, \mathrm{FE}, \mathrm{ALG}, \mathrm{EC}, \mathrm{SS}, \mathrm{RLG}, \mathrm{RJD}, \mathrm{KMH}$, WAC. ABP, OP, SSG, FE, ALG, EC, and SS oversaw the implementation. ABP and PLH wrote the first draft of the manuscript, with input from SM. SM and JLM conducted the statistical analyses. All authors read and approved the final manuscript.

\section{Author details}

${ }^{1}$ Lata Medical Research Foundation, Nagpur, Maharashtra 440022, India. ${ }^{2}$ RTI International, Research Triangle Park, North Carolina 27709, USA

${ }^{3}$ Department of Community Health Sciences \& Family Medicine, Aga Khan University, Karachi, Pakistan. ${ }^{4}$ KLE University's JN Medical College, Belgaum, Karnataka, India. ${ }^{5}$ Moi University School of Medicine, Eldoret, Kenya.

${ }^{6}$ IMSALUD, San Carlos University, Guatemala City, Guatemala. ${ }^{7}$ University Teaching Hospital, Lusaka, Zambia. ${ }^{8}$ Center for Research of Mothers and Children, NIH, Rockville, MD 20852, USA. ${ }^{9}$ Department of Pediatrics, Indiana University School of Medicine, Indianapolis, IN 46202, USA. ${ }^{10}$ Department of Obstetrics/Gynecology, Columbia University, New York, NY 10032, USA.

${ }^{11}$ Department of OB-GYN, Christiana Care, Newark, DE 19718, USA.

${ }^{12}$ Department of Pediatrics, University of Colorado, Aurora, CO 80045, USA.

${ }^{13}$ Department of Pediatrics, University of Alabama at Birmingham, Birmingham, AL 35233, USA. ${ }^{14}$ Division of Global Health, Department of Pediatrics, Massachusetts General Hospital, Boston, MA 02114, USA.

Received: 13 January 2015 Accepted: 25 May 2015

Published online: 21 July 2015

\section{References}

1. Rajaratnam JK, Marcus JR, Flaxman AD, Wang H, Levin-Rector A, et al. Neonatal, postneonatal, childhood, and under-5 mortality for 187 countries, 1970-2010: a systematic analysis of progress towards Millennium Development Goal 4. Lancet. 2010;375:1988-2008. doi:10.1016/S01406736(10)60703-9.

2. Lozano R, Wang H, Foreman KJ, Rajaratnam JK, Naghavi M, et al. Progress towards millennium development goals 4 and 5 on maternal and child mortality: an updated systematic analysis. Lancet. 2011;378:1139-65. doi:10.1016/S0140-6736(11)61337-8.

3. Lawn JE, Lee AC, Kinney M, Sibley L, Carlo WA, et al. Two million intrapartum-related stillbirths and neonatal deaths: where, why, and what can be done? Int J Gynaecol Obstet. 2009;107 Suppl 1: S5-18, S19. doi:10.1016/j.ijgo.2009.07.016.

4. Liu L, Oza S, Hogan D, Perin J, Rudan I, et al. Global, regional, and national causes of child mortality in 2000-13, with projections to inform post-2015 priorities: an updated systematic analysis. Lancet. 2014. doi:10.1016/S01406736(14)61698-6. 
5. Goldenberg RL, McClure EM, Kodkany B, Wembodinga G, Pasha O, et al. A multi-country study of the "intrapartum stillbirth and early neonatal death indicator" in hospitals in low-resource settings. Int J Gynaecol Obstet. 2013;122:230-3. doi:10.1016/j.ijgo.2013.04.008.

6. Bang A, Bellad R, Gisore P, Hibberd P, Patel A, et al. Implementation and evaluation of the helping babies breathe curriculum in three resource limited settings: does helping babies breathe save lives? a study protocol. BMC Pregnancy Childbirth. 2014;14:116-1471. doi:10.1186/1471-2393-14-116.

7. Gordon SB, Bruce NG, Grigg J, Hibberd PL, Kurmi OP, et al. Respiratory risks from household air pollution in low and middle income countries. Lancet Respir Med. 2014;2:823-60. doi:10.1016/S2213-2600(14)70168-7.

8. World Health Organization. Indoor Air Pollution and Health; 2011. www.who.int/mediacentre/factsheets/fs292/en.

9. Lim SS, Vos T, Flaxman AD, Danaei G, Shibuya K, et al. A comparative risk assessment of burden of disease and injury attributable to 67 risk factors and risk factor clusters in 21 regions, 1990-2010: a systematic analysis for the Global Burden of Disease Study 2010. Lancet. 2012;380:2224-60. doi:10.1016/S0140-6736(12)61766-8

10. Bruce NG, Dherani MK, Das JK, Balakrishnan K, Adair-Rohani H, et al. Control of household air pollution for child survival: estimates for intervention impacts. BMC Public Health. 2013;13 Suppl 3:S8. doi:10.1186/1471-2458-13-S3-S8.

11. Wylie BJ, Coull BA, Hamer DH, Singh MP, Jack D, et al. Impact of biomass fuels on pregnancy outcomes in central East India. Environ Health. 2014;13:1. doi:10.1186/1476-069X-13-1.

12. Martin WJ, Glass RI, Araj H, Balbus J, Collins FS, et al. Household air pollution in low- and middle-income countries: health risks and research priorities. PLoS Med. 2013;10:e1001455. doi:10.1371/journal.pmed.1001455.

13. Juarez SP, Merlo J. Revisiting the effect of maternal smoking during pregnancy on offspring birthweight: a quasi-experimental sibling analysis in Sweden. PLoS One. 2013;8:e61734. doi:10.1371/journal.pone.0061734.

14. Cnattingius S, Nordstrom ML. Maternal smoking and feto-infant mortality: biological pathways and public health significance. Acta Paediatr. 1996;85:1400-2.

15. Pineles BL, Park E, Samet JM. Systematic review and meta-analysis of miscarriage and maternal exposure to tobacco smoke during pregnancy. Am J Epidemiol. 2014;179:807-23. doi:10.1093/aje/kwt334.

16. Goudar SS, Carlo WA, McClure EM, Pasha O, Patel A, et al. The maternal and newborn health registry study of the global network for Women's and Children's health research. Int J Gynaecol Obstet. 2012;118:190-3. doi:10.1016/j.ijgo.2012.04.022.

17. USAID. DHS Program; 2014. http://www.dhsprogram.com.

18. Pope DP, Mishra V, Thompson L, Siddiqui AR, Rehfuess EA, et al. Risk of low birth weight and stillbirth associated with indoor air pollution from solid fuel use in developing countries. Epidemiol Rev. 2010;32:70-81. doi:10.1093/ epirev/mxq005.

19. VanderWeele TJ, Mumford SL, Schisterman EF. Conditioning on intermediates in perinatal epidemiology. Epidemiology. 2012;23:1-9. doi:10.1097/EDE.0b013e31823aca5d.

20. Wilcox AJ, Weinberg CR, Basso O. On the pitfalls of adjusting for gestational age at birth. Am J Epidemiol. 2011;174:1062-8. doi:10.1093/aje/kwr230.

21. Hernandez-Diaz S, Schisterman EF, Hernan MA. The birth weight "paradox" uncovered? Am J Epidemiol. 2006;164:1115-20. doi:10.1093/aje/kwj275.

22. De RM, Worku HM. A warning concerning the estimation of multinomial logistic models with correlated responses in SAS. Comput Methods Programs Biomed. 2012;107:341-6.

23. Kadir MM, McClure EM, Goudar SS, Garces AL, Moore J, et al. Exposure of pregnant women to indoor air pollution: a study from nine low and middle income countries. Acta Obstet Gynecol Scand. 2010;89:540-8. doi:10.3109/ 00016340903473566

24. Epstein MB, Bates MN, Arora NK, Balakrishnan K, Jack DW, et al. Household fuels, low birth weight, and neonatal death in India: the separate impacts of biomass, kerosene, and coal. Int J Hyg Environ Health. 2013;216:523-32. doi:10.1016/j.ijheh.2012.12.006.

25. Lakshmi PV, Virdi NK, Sharma A, Tripathy JP, Smith KR, et al. Household air pollution and stillbirths in India: analysis of the DLHS-II National Survey. Environ Res. 2013;121:17-22. doi:10.1016/j.envres.2012.12.004.

26. Jehan I, Harris H, Salat S, Zeb A, Mobeen N, et al. Neonatal mortality, risk factors and causes: a prospective population-based cohort study in urban Pakistan. Bull World Health Organ. 2009;87:130-8.

27. Tielsch JM, Katz J, Thulasiraj RD, Coles CL, Sheeladevi S, et al. Exposure to indoor biomass fuel and tobacco smoke and risk of adverse reproductive outcomes, mortality, respiratory morbidity and growth among newborn infants in south India. Int J Epidemiol. 2009:38:1351-63. doi:10.1093/ije/dyp286

28. Boy $\mathrm{E}$, Bruce N, Delgado $\mathrm{H}$. Birth weight and exposure to kitchen wood smoke during pregnancy in rural Guatemala. Environ Health Perspect. 2002;110:109-14

29. Mavalankar DV, Gray RH, Trivedi CR. Risk factors for preterm and term low birthweight in Ahmedabad, India. Int J Epidemiol. 1992;21:263-72.

30. Mishra V, Dai X, Smith KR, Mika L. Maternal exposure to biomass smoke and reduced birth weight in Zimbabwe. Ann Epidemiol. 2004;14:740-7.

31. Siddiqui AR, Gold EB, Yang X, Lee K, Brown KH, et al. Prenatal exposure to wood fuel smoke and low birth weight. Environ Health Perspect. 2008;116:543-9. doi:10.1289/ehp.10782.

32. Lawn JE, Blencowe H, Oza S, You D, Lee AC, et al. Every Newborn: progress, priorities, and potential beyond survival. Lancet. 2014;384:189-205. doi:10.1016/S0140-6736(14)60496-7.

33. Madhavan ND, Naidu KA. Polycyclic aromatic hydrocarbons in placenta, maternal blood, umbilical cord blood and milk of Indian women. Hum Exp Toxicol. 1995;14:503-6.

34. Rossner Jr P, Milcova A, Libalova H, Novakova Z, Topinka J, et al. Biomarkers of exposure to tobacco smoke and environmental pollutants in mothers and their transplacental transfer to the foetus. Part II. Oxidative damage. Mutat Res. 2009;669:20-6. doi:10.1016/ j.mrfmmm.2009.04.010.

35. Sram RJ, Beskid O, Rossnerova A, Rossner P, Lnenickova Z, et al. Environmental exposure to carcinogenic polycyclic aromatic hydrocarbons-the interpretation of cytogenetic analysis by FISH. Toxicol Lett. 2007;172:12-20. doi:10.1016/ j.toxlet.2007.05.019.

36. Topinka J, Milcova A, Libalova H, Novakova Z, Rossner Jr P, et al. Biomarkers of exposure to tobacco smoke and environmental pollutants in mothers and their transplacental transfer to the foetus. Part I: bulky DNA adducts. Mutat Res. 2009;669:13-9. doi:10.1016/j.mrfmmm.2009.04.011.

37. Hatch MC, Warburton D, Santella RM. Polycyclic aromatic hydrocarbon-DNA adducts in spontaneously aborted fetal tissue. Carcinogenesis. 1990;11:1673-5

38. Sanyal MK, Mercan D, Belanger $K$, Santella RM. DNA adducts in human placenta exposed to ambient environment and passive cigarette smoke during pregnancy. Defects Res A Clin Mol Teratol. 2007;79:289-94. doi:10.1002/bdra.20346

39. Singh VK, Singh J, Anand M, Kumar P, Patel DK, et al. Comparison of polycyclic aromatic hydrocarbon levels in placental tissues of Indian women with full- and preterm deliveries. Int J Hyg Environ Health. 2008;211:639-47. doi:10.1016/j.ijheh.2007.11.004.

40. Huel G, Girard F, Nessmann C, Godin J, Blot P, et al. Placental aryl hydrocarbon hydroxylase activity and placental calcifications. Toxicology. 1992;71:257-66.

41. Huel G, Godin J, Frery N, Girard F, Moreau T, et al. Aryl hydrocarbon hydroxylase activity in human placenta and threatened preterm delivery. J Expo Anal Environ Epidemiol. 1993:3 Suppl 1:187-99.

42. Huel G, Godin J, Moreau T, Girard F, Sahuquillo J, et al. Aryl hydrocarbon hydroxylase activity in human placenta of passive smokers. Environ Res. 1989;50:173-83.

43. Arnould JP, Verhoest P, Bach V, Libert JP, Belegaud J. Detection of benzo[a]pyrene-DNA adducts in human placenta and umbilical cord blood. Hum Exp Toxicol. 1997;16:716-21.

44. Dejmek J, Selevan SG, Benes I, Solansky I, Sram RJ. Fetal growth and maternal exposure to particulate matter during pregnancy. Environ Health Perspect. 1999:107:475-80.

45. Dejmek J, Solansky I, Benes I, Lenicek J, Sram RJ. The impact of polycyclic aromatic hydrocarbons and fine particles on pregnancy outcome. Environ Health Perspect. 2000;108:1159-64.

46. Perera FP, Rauh V, Tsai WY, Kinney P, Camann D, et al. Effects of transplacental exposure to environmental pollutants on birth outcomes in a multiethnic population. Environ Health Perspect. 2003;111:201-5.

47. Perera FP, Whyatt RM, Jedrychowski W, Rauh V, Manchester D, et al. Recent developments in molecular epidemiology: a study of the effects of environmental polycyclic aromatic hydrocarbons on birth outcomes in Poland. Am J Epidemiol. 1998;147:309-14.

48. Sioutas C, Delfino RJ, Singh M. Exposure assessment for atmospheric ultrafine particles (UFPs) and implications in epidemiologic research. Environ Health Perspect. 2005;113:947-55 
49. Nel AE, Diaz-Sanchez D, Li N. The role of particulate pollutants in pulmonary inflammation and asthma: evidence for the involvement of organic chemicals and oxidative stress. Curr Opin Pulm Med. 2001;7:20-6.

50. Li N, Sioutas C, Cho A, Schmitz D, Misra C, et al. Ultrafine particulate pollutants induce oxidative stress and mitochondrial damage. Environ Health Perspect. 2003;111:455-60.

51. Engel SA, Erichsen HC, Savitz DA, Thorp J, Chanock SJ, et al. Risk of spontaneous preterm birth is associated with common proinflammatory cytokine polymorphisms. Epidemiology. 2005;16:469-77.

52. Keelan JA, Blumenstein M, Helliwell RJ, Sato TA, Marvin KW, et al. Cytokines, prostaglandins and parturition-a review. Placenta. 2003;24 Suppl A:S33-S46.

53. Wei SQ, Fraser W, Luo ZC. Inflammatory cytokines and spontaneous preterm birth in asymptomatic women: a systematic review. Obstet Gynecol. 2010;116:393-401. doi:10.1097/AOG.0b013e3181e6dbc0.

54. Gomez C, Berlin I, Marquis P, Delcroix M. Expired air carbon monoxide concentration in mothers and their spouses above $5 \mathrm{ppm}$ is associated with decreased fetal growth. Prev Med. 2005;40:10-5. doi:10.1016/j.ypmed.2004.04.049.

\section{Submit your next manuscript to BioMed Central and take full advantage of:}

- Convenient online submission

- Thorough peer review

- No space constraints or color figure charges

- Immediate publication on acceptance

- Inclusion in PubMed, CAS, Scopus and Google Scholar

- Research which is freely available for redistribution 